\title{
Polymer Electrolyte Membrane Fuel Cells (PEMFC) in Automotive Applications: Environmental Relevance of the Manufacturing Stage
}

\author{
Daniel Garraín, Yolanda Lechón, Cristina de la Rúa \\ Energy Systems Analysis Unit, Energy Department, CIEMAT (Public Research Centre on Energy, Environment and Technologies), \\ Spanish Ministry of Science and Innovation, Madrid, Spain. \\ Email: daniel.garrain@ciemat.es
}

Received January $31^{\text {st }}$, 2011; revised March $11^{\text {th }}$, 2011; accepted March $14^{\text {th }}, 2011$.

\begin{abstract}
This study presents a state of the art of several studies dealing with the environmental impact assessment of fuel cell (FC) vehicles and the comparison with their conventional fossil-fuelled counterparts, by means of the Life Cycle Assessment (LCA) methodology. Results declare that, depending on the systems characteristics, there are numerous environmental advantages, but also some disadvantages can be expected. In addition, the significance of the manufacturing process of the FC, more specifically the Polymer Electrolyte Membrane Fuel Cell (PEMFC) type, in terms of environmental impact is presented. Finally, CIEMAT's role in HYCHAIN European project, consisting of supporting early adopters for hydrogen FCs in the transport sector, is highlighted.
\end{abstract}

Keywords: Fuel Cell (FC), Polymer Electrolyte Membrane Fuel Cell (PEMFC), Life Cycle Assessment (LCA), Greenhouse Gases (GHG) Emissions, Global Warming Impact Category, Energy Resources Impact Category, Acidification Impact Category, Vehicle Manufacturing Phase

\section{Introduction}

Fuel cells (FC) are electrochemical devices that use hydrogen, or hydrogen-rich fuels, together with oxygen from air, to produce electricity and heat. There are variants of this basic process, depending on FC types and fuels [1].

FC systems can be used in portable, transport and stationary applications. Depending on the type of FCs, stationary applications include small residential, mediumsized cogeneration or large power plant applications. They can be applied in various stationary applications, ranging from one $\mathrm{kW}$ systems for domestic heating, combined heat and power production (CHP) for district heating or large buildings, up to megawatt applications for industrial cogeneration and electricity production without cogeneration. In each of these applications, different conventional systems are already well established (gas engine CHP, gas turbines or combined cycle power plants) [2-4].

In the mobile sector, FCs, particularly low-temperature FCs, can be used for heavy-duty and passenger vehicles, for trains, boats or auxiliary power units for air planes.
Mobile applications also include portable low power systems for various uses. All the major automotive manufacturers have a FC vehicle either in development or in testing right now and several have begun leasing and testing in larger quantities. Commercialization is a little further down the line (some automakers say 2012, others later), but every demonstration helps bring that date closer.

Polymer Electrolyte Membrane Fuel Cell (PEMFC) is a type of proton exchange FC that takes its name from the special plastic membrane used as the electrolyte. Typical cell components within a PEMFC stack include: the ion exchange membrane, an electrically conductive porous backing layer, an electro-catalyst (the electrodes) at the interface between the backing layer and the membrane, and cell interconnects and flow plates that deliver the fuel and oxidant to reactive sites via flow channels and electrically connect the cells. The most common material for this membrane is Nafion ${ }^{\circledR}$, a perfluorinated sulphonic acid polymer. The membrane is comprised between the two porous carbon electrodes coated with a minimum 
amount of platinum catalyst. Platinum is essential for the reaction to take place, due to the low operating temperature of this type of FC, and it is highly sensible to any carbon monoxide content in the fuel, which may poison the catalyst in a short time. The assembly of the membrane and the electrodes is called membrane electrode assembly (MEA). A stack is composed by a series of single cells separated by bipolar plates with integrated gas flow channels. Bipolar plates may be either metallic of made of carbon composite [2,3]. Figures $\mathbf{1}$ and $\mathbf{2}$ show the PEMFC concept and a schematic PEMFC stack respectively.

The fuel gas (usually hydrogen) and the oxidant (air or oxygen) are supplied to the MEA passing through a series of plates, which have the purpose to diffuse them in the most uniform way to the two membrane sides. A PEMFC transforms the chemical energy liberated during the electrochemical reaction of hydrogen and oxygen to electrical or thermal energy. The exothermic redox reac-

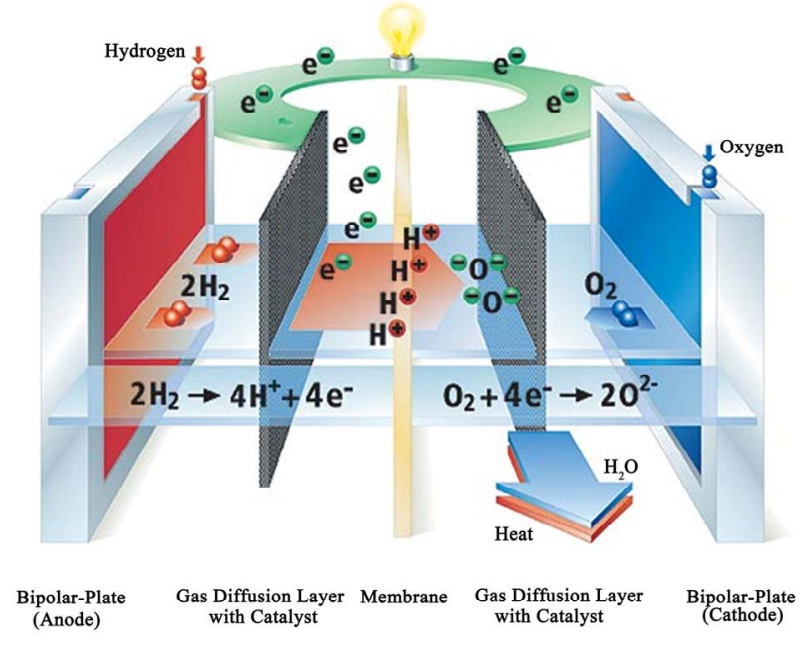

Figure 1. PEMFC single cell (http://www.bloggang.com).

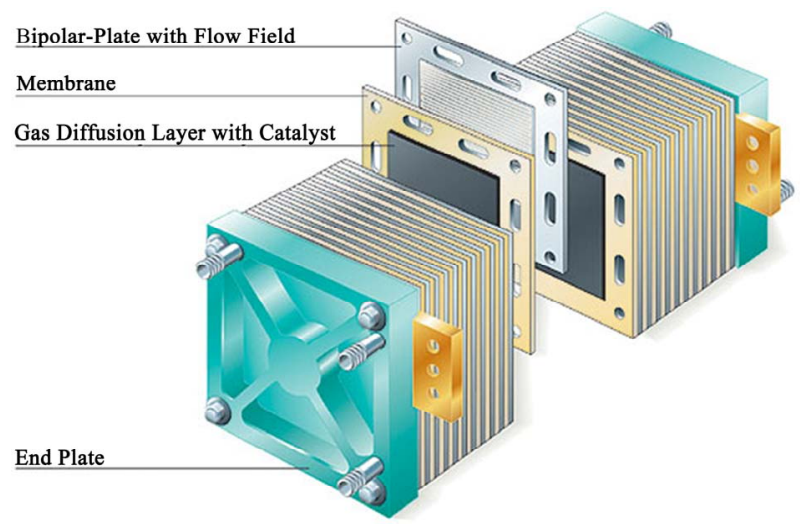

Figure 2. PEMFC stack cell (http://www.bloggang.com). tion is shown in Figure 1. A stream of hydrogen is delivered to the anode side of the MEA. At the anode side it is catalytically split into protons and electrons, conducting the oxidation reaction. These protons permeate through the polymer electrolyte membrane to the cathode side. The electrons travel along an external load circuit to the cathode side of the MEA, thus creating the current output of the FC. In the meantime, a flow of oxygen is delivered to the cathode side of the MEA. Then, at this side oxygen molecules are reduced and, subsequently, react with the protons permeating through the membrane to form water molecules and to liberate heat.

PEMFC technology is able to efficiently generate high power density, thereby making the technology potentially attractive for automotive applications since it can offer efficient energy conversion in a compact and robust package. Size and reliability are related to the simplicity of the system, which in turn is influenced by the choice of stack cooling strategy. In comparison with other types of FC technologies, PEMFC is more suitable for transportation mainly due to its high power density and a low operating temperature. In turn, the start-up time is short $[5,6]$.

\section{Environmental Life-Cycle Impact Studies of PEMFC for Mobile Applications}

Interest in hydrogen as a fuel for transportation applications has developed as a consequence of increasing social awareness of environmental degradation (i.e. global warming effect, exhausting crude oil stocks, etc.) and the possibilities of reducing it by selecting more environmentally-friendly energy systems. FC is an energy system with a high potential for green energy conversion.

The efficiency of applying hydrogen technologies, such as PEMFC vehicles, depends on the characteristics of the many steps and chains involved, which include production, distribution and, finally, conversion of the chemical energy of hydrogen into mechanical work in a vehicle [7]. Adequate evaluation of environmental impact and energy consumption throughout the overall hydrogen production and utilization life cycle, in comparison with that for mineral fuels, is critical for making proper strategic decisions about its competitiveness in the future [8].

Life cycle assessment (LCA) is a methodology for this type of assessment. ISO 14040:2006 and ISO 14044: 2006 standards [9-10] define LCA as a methodology for the comprehensive assessment of the impact that a product or process has on the environment throughout its life span (from extraction of raw materials through manufacturing, logistics and use to scrapping and recycling, if any), which is known as a 'from cradle-to-grave' analysis,

According to these ISO standards, a LCA study basi- 
cally consists of four steps: goal and scope definition, life cycle inventory (LCI) analysis, life cycle impact assessment (LCIA) and interpretation of the results. The most time and effort consuming stage is the LCI, which entails data collection and calculation procedure to quantify relevant inputs and outputs. These input and output flows involve consumed or produced goods as well as emissions, waste streams, etc. It is essential to consider all life-cycle stages, i.e., system production, operation and disposal/recycling. Principally, there will be iterative steps leading to additional data requirements. The data collection usually follows the process chain, i.e., extraction, conversion, transport, production, use and disposal or recycling, respectively. The phases might as well be divided into smaller phases, the so-called unit processes. Every unit process of the chain has several incoming and outgoing material and energy flows that are carefully recorded. The main product or the co-products, energy carriers, wastes and emissions into air, water or soil are outputs leaving the system boundaries. The potential impacts of the inputs and outputs of the LCI are then determined by the impact assessment, which categorizes and aggregates the input and output flows to the biosphere to so-called impact categories (such as the global warming, energy resources depletion, acidification, eutrophication, etc.), by multiplication with standardized characterization factors.

Nevertheless, LCA method always involves some subjectivity and uncertainty, especially when the analysis concerns new technologies.

'Well-to-Wheel' (WtW) analysis is the specific LCA of the efficiency of fuels used for road transportation. WtW is often broken down into two stages titled 'Well- to-Tank' (WtT) (which incorporates the feedstock, fuel processes and transport to the petrol station) and 'Tank-to-Wheel' (TtW) (that deals with vehicle operation). WtW analyses usually exclude manufacturing of the vehicle and FC stages.

\subsection{LCA of FC Versus Internal Combustion EEngine (ICE) Vehicles}

EUCAR, CONCAWE and the Joint Research Centre (JRC) of the EU Commission have published their joint study (JEC) [11] about the evaluation of the WtW energy use and greenhouse gases (GHG) emissions for a wide range of potential future fuel and powertrain options. In the case of hydrogen as a substitute fuel, they have considered a large number of alternatives hydrogen pathways. It must be considered that the FC manufacturing process is not included in the environmental assessment. The study remarks that hydrogen as a transportation fuel conjures up images of quiet, efficient, non-polluting vehicles and is therefore the focus of much attention. Reality is of course more complex and both the desirability to develop hydrogen as a road fuel and the way to get there need to be considered very carefully. Although hydrogen can be used in an ICE, the real efficiency breakthrough comes from FCs. Main results in terms of the energy use and GHG emissions, regarding to different vehicle technology, highlight that if hydrogen is produced from natural gas (NG), WtW GHG emissions savings can only be achieved if hydrogen is used in FC instead of ICE vehicles.

Pehnt $[4,12,13]$ has developed several LCA studies in the field of FCs. They have been focused on the discussion of the main stages used in the analyses, showing some respective results and conclusions and also identifying knowledge deficits that require further research with vehicles. Results from the different life cycle stages have been put together to obtain a complete performance of the different power train and fuel options. For the FC applications in passenger cars (PEMFC), the fuel, especially the primary energy carrier, is the main contributor for results in the environmental impact categories 'energy resources' and 'global warming'. The use of fossil hydrogen in FCs leads to a relatively low reduction of global warming compared to the ICE, mainly due to the lower efficiency of hydrogen production compared to gasoline. Figure 3 highlights the vehicle manufacturing stage in the whole LCA of a FC vehicle based on methanol in percentage terms. The most significant impact categories, namely global warming, energy resources depletion and acidification were considered. Vehicle manufacturing stage is of special importance in the acidification impact category and it should not be neglected in the rest of illustrated categories.

Sorensen [14] have issued the environmental LCA data for several passengers cars (FC equipped with PEMFC stacks versus conventional vehicles), in terms of energy used and emissions occurring during the phases of the vehicle life-cycle, based on some bibliographical studies with addition of own calculations and estimates. The impacts have been translated into concrete impacts on health and environment.

Table 1 summarizes main impact categories results of these studies in the same units. These are not comparable because of the different considerations (type of vehicle, raw materials, system boundaries in LCA, etc.) of each author. In order to calculate the impacts from the vehicle production in such a detail in these studies, an important effort has been done at the LCI stage. Therefore, main data according to the vehicle parts production has been carried out using industry data from data collection sheets, and published international databases in case of not provided data. 

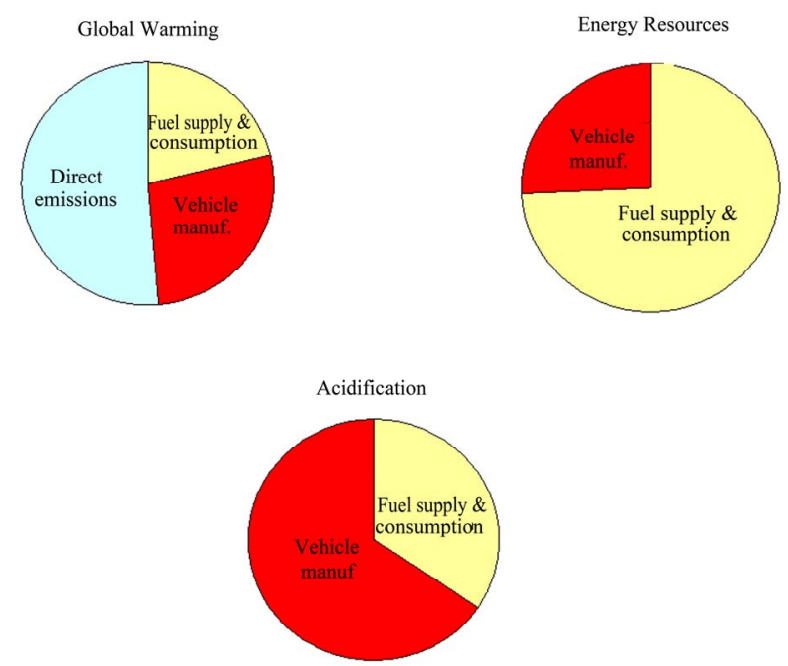

Figure 3. Environmental contribution of main stages in the entire life cycle of a FC vehicle based on methanol (adaptation of [12]).

Ally [15] performed a LCA study in order to evaluate the environmental impacts of the hydrogen FC bus transportation system (including the fuel infrastructure, bus manufacture, operation, and disposal), comparing the shares with the established diesel and compressed natural gas (CNG) bus transportation systems in the city of Perth (Australia). Results highlight that the global warming potential of the FC buses is slightly worse than diesel bus fleet, and slightly better than CNG bus fleet. Sensitivity analyses were conducted to examine the effects of expected hydrogen and FC innovations and found that a reduction of greater than $50 \%$ is achievable in the main impact categories in LCA.

Granovskii et al. [16] have conducted a LCA of hydrogen and gasoline vehicles, including fuel production and utilization in vehicles powered by FCs and ICE, in- order to evaluate and compare their efficiencies and environmental impacts. In this study, the hydrogen life cycles, for a variety of methods for hydrogen production, were compared with the life cycle of gasoline. This comparison was done to obtain the critical efficiency of a hydrogen PEMFC stack, which allows it to be energetically competitive with the ICE. The comparison was performed based on fossil fuel energy consumption and GHG emissions. It must be remarked that the FC manufacturing stage is not included in the environmental assessment. Results indicate that the efficiency of a FC vehicle employing hydrogen from NG should be at least 25\% - 30\% higher than a gasoline one to be competitive.

\subsection{LCA of PEMFC Stacks in FC Vehicles}

Previous studies consider the full life cycle of a FC vehicle, but only two of them include and detail the manufacturing processes and data of the components of a FC stack.

The most complete and important is the study of Pehnt [12], which reported a detailed life-cycle data of a FC vehicle. Industry data from Ballard were considered for the PEMFC stack production (platinum group metals (PGM) included in the gas diffusion electrode (GDE), natural and synthetic graphite, membrane, etc.). PGM are mainly extracted in South Africa and Russia as a by-product of nickel mining. In determining the allocation rules for PGM extraction, Pehnt concluded that the process should be allocated on an economic basis. A PGM recycling rate of $75 \%$ was assumed for the base case.

Figure 4 shows the shared environmental contribution of the PEMFC stack production in the manufacture of a FC vehicle based on methanol (from results of Figure 2), considering the most important impact categories.

The environmental life cycle inventory of Sorensen [14]

Table 1. Environmental performance of FC and ICE vehicles options by author.

\begin{tabular}{|c|c|c|c|c|c|}
\hline Reference & Type of engine & Fuel & $\mathrm{ER}(\mathrm{MJ} / \mathrm{km})^{*}$ & $\mathrm{GW}\left(\mathrm{g} \mathrm{CO}_{2} \mathrm{eq} / \mathrm{km}\right)$ & $\mathrm{A}\left(\mathrm{mg} \mathrm{SO} \mathrm{Se}_{2} / \mathrm{km}\right)$ \\
\hline \multirow{2}{*}{ JEC [11] } & FC & $\mathrm{H}_{2}$ from $\mathrm{NG}$ & $1.40-1.75$ & $75-105$ & n.a. \\
\hline & ICE & Diesel & $1.90-2.10$ & $150-165$ & n.a. \\
\hline \multirow{5}{*}{ Pehnt [4,12-13] } & FC (PEMFC) & $\mathrm{H}_{2}$ from $\mathrm{NG}$ & 2.05 & 140 & 240 \\
\hline & FC (PEMFC) & Methanol & 2.76 & 160 & 290 \\
\hline & ICE & $\mathrm{H}_{2}$ from $\mathrm{NG}$ & 2.54 & 175 & 295 \\
\hline & ICE & Gasoline & 2.16 & 160 & 320 \\
\hline & ICE & Diesel & 2.05 & 145 & 380 \\
\hline \multirow{4}{*}{ Sorensen [14] } & FC (PEMFC) & $\mathrm{H}_{2}$ from $\mathrm{NG}$ & 1.74 & 120 & 120 \\
\hline & FC (PEMFC) & $\mathrm{H}_{2}$ from wind & 1.74 & 34 & 120 \\
\hline & ICE & Diesel (EU) & 1.60 & 97 & 74 \\
\hline & ICE & Gasoline (USA) & 3.54 & 262 & 203 \\
\hline
\end{tabular}

*Results have been adapted to LHV base; n.a.: not available; ER: Energy Resources; GW: Global Warming; A: Acidification. 

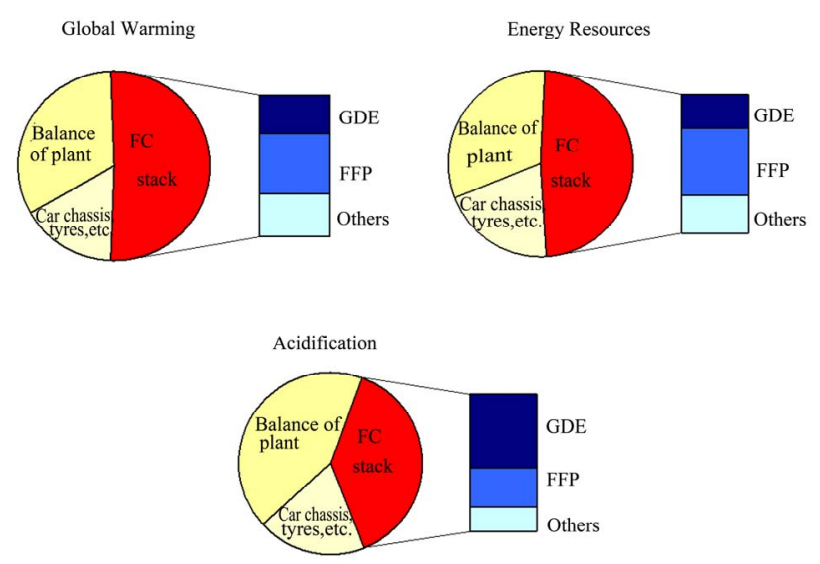

Figure 4. Environmental contribution of main PEMFC stack components in the manufacture of a FC vehicle based on methanol (adaptation of [12]) (GDE: Gas Diffusion Electrode; FFP: Flow Field Plate).

for PEMFC stacks components is based on Pehnt's studies $[12,13]$, with no recycling assumed. Results show a very similar performance as Figure 2, presenting a contribution of $50 \%, 47 \%$ and $40 \%$ in global warming, energy resources and acidification impact categories respectively.

\section{Discussion and Conclusions}

Discussion about the results of the previous studies is going to be assessed with focus on three environmental aspects: differences between FC and ICE vehicles, relevance of the production stage in PEMFC stacks, and finally, the use of alternative/renewable energy systems to produce hydrogen for FCs. At that time, the most important findings and future outlooks will be highlighted.

\subsection{FC and ICE Vehicles}

Results of Table 1 confirm that environmental advantages, but also some disadvantages, can be expected in the assessment of FC against ICE vehicles. These results could depend on the FC technology, the application area, the input fuel or the baseline technology.

FC vehicles are promising energy converters for mobile applications. Studies from US Department of Energy $[17,18]$ state that they are expected to achieve energy efficiencies of $40 \%$ - 55\%, life time of 5,000 hours and lower costs in 2015. So, FC passenger vehicles are expected to be up to three times more efficient than internal combustion engines, which now operate at $10 \%-16 \%$ efficiency $[17,18]$. Given this significant improvement, these vehicles would offer substantial reductions in GHG emissions, and higher mileage too. Moreover, other neglected impact categories could be improved by the use of
FC technology in vehicles. Because they operate with electric motors which have very few moving parts (only those pumps and blowers needed to provide fuel and coolant), vehicle vibrations and noise could be vastly reduced and routine maintenance (oil changes, spark plug replacement) could be eliminated [18].

\subsection{PEMFC Stacks}

Figure 3 shows an environmental impact contribution of the stack around $40 \%-50 \%$ in the whole LCA of the vehicle. Combining the values of Figures 3 and 4, the production of FC stacks leads to environmental impacts which cannot be neglected compared to the impacts of the utilization phase.

The most significant contributors to the emissions profile are the $\mathrm{SO}_{2}$ emissions from extraction and processing of PGM, and the energy consumption to manufacture bipolar plates [12]. Analysing the contribution of the stack production further, two components turn out to be of special relevance. The GDE is responsible for a large share of the total acidification and, to a lesser degree, the GHG emissions. The crucial materials causing the high acidification are PGM used as catalysts, due to the emissions during the pyrometallurgical treatment of the material. The flow field plate (FFP) is the second important component, particularly because of the electricity input for resin impregnation of the plate. Fundamentally, the energy required for fuel stack production is driven up by the use of graphite [12].

The manufacturing process itself has a very low impact compared to the rest of stages and materials, so it has been included in 'others' contribution part.

Higher production volumes could further reduce the specific energy consumption. It is interesting that the graphitic materials, commonly considered as a main ecological factor, contribute less GHG emissions to the total than the electricity consumption. This is a result of the efforts to reduce the weight of the flow plates. Pehnt determines the change in ecological footprint due to recycling, and concludes that there is great promise in recycling the PGM to improve the FC stack life cycle [12, 15].

\subsection{Alternative Hydrogen Production Processes}

Table 1 illustrates that the process of selecting the fuelcould be generally of higher environmental relevance than the energy converter. The fact of choosing either hydrogen or methanol as a fuel for FC can lead to quite different environmental profiles. Pehnt's studies $[4,12,13]$ state a reduction of $25 \%$ in energy resources consumption, $12 \%$ in GHG emissions and $8 \%$ in acidification gases because 
of selecting hydrogen as a fuel for FC.

The study of Sorensen [14] has verified that the use of renewable energy (wind versus NG) to produce hydrogen would achieve lesser emissions of GHG (see Table 1). Nevertheless, other publications [19] have verified that renewable energy would achieve greater reduction of GHG emissions by displacing the existing fossil fuel electricity generation systems, rather than using renewables to produce hydrogen. While this is true in the global environmental context, energy independence and local air quality are important concerns that can only be addressed by a cleaner and sustainable transport fuel. Some of the important benefits of hydrogen vehicle technology include a substantial increase in efficiency, and a moderated transition from fossil primary energy sources to renewables. So, LCA is a tool that can be used by decision makers to quantify and compare these difficult and sometimes conflicting objectives [15].

\section{Hychain Mini-Trans Project}

The HYCHAIN MINI-TRANS project is an Integrated Project funded through the 6th Framework Programme of the European Union. It is one of the leading demonstration projects of the European Commission's Transportation and Energy Division. The project started in 2006 and will end in mid-2011. This project deploys several fleets of innovative FC vehicles (wheelchair, cargobike, scooter, utility vehicle and midibus) in four regions of Europe (France, Spain, Germany and Italy) operating on hydrogen. The project aims to support early adopters for hydrogen FCs in the transport sector, in segments where the market has the best chances to continue to grow in a sustainable mode beyond this initiative. It will thus open the path to achieving large-scale use of hydrogen used as an energy carrier and FCs as efficient energy converters. More info is available at http://www. hychain.org.

CIEMAT's role in this project is the development of the environmental impact assessment studies and the coordination of the socioeconomics studies for Spain. At present (January 2011), Energy System Analysis Unit from CIEMAT is carrying out the explorative environmental impact assessment for identifying the major impacts related to the life-cycle of HYCHAIN applications from production to decommissioning and disposal. By selecting components of the HYCHAIN process chain that are markedly different to those of reference technologies (ICE and FC vehicles), the study of environmental impacts is focusing on FC manufacturing, manufacturing of storage equipment, and the final disposal/recycling of the storage technologies and the FCs after their life time. The main environmental aspects to be assessed will be the following:

1) Use of fossil and primary energy.

2) Consumption and origin of scarce materials (platinum and other metals).

3) GHG emissions.

Other important pollutant emissions $\left(\mathrm{NO}_{\mathrm{x}}, \mathrm{SO}_{2}, \mathrm{CO}\right.$, PM, NMVOC, etc.) and their associated environmental impacts.

\section{REFERENCES}

[1] IEA, "Fuel Cells,” IEA Energy Technology Essentials, 2007. http://www.iea.org/techno/essentials6.pdf

[2] USDE, "Fuel Cell Handbook,” 7th Edition, EG\&G Technical Services, Inc., Morgantown, U.S. Department of Energy, Office of Fossil Energy, National Energy Technology Laboratory, 2004.

[3] R. Gerboni, M. Pehnt, P. Viebahn and E. Lavagno (Eds), "Final Report on Technical Data, Costs and Life Cycle Inventories of Fuel Cells,” Deliverable no 9.2 - RS 1 $1^{\text {a }}$, New Energy Externalities Developments for Sustainability Project, 6th Framework Programme, 2008.

[4] M. Pehnt, "Life-Cycle Analysis of Fuel System Components," Handbook of Fuel Cells-Fundamentals, Technology and Applications, Edited by W. Vielstich, H. A. Gasteiger and A. Lamm, John Wiley \& Sons, Ltd., Chichester, Vol. 4, Part 13, Chapter 94, 2003, pp. 1293-1317.

[5] P. Adcock, A. Kells and C. Jackson, "PEM Fuel Cell for Road Vehicles," Proceedings of the 3rd European EleDrive Transportation Conference, International Advanced Mobility Forum, Geneva, 11-13 March 2008.

[6] N. Meng, M. K. H. Leung, D. Y. C. Leung and K. Sumathy "Prospect of Proton Exchange Membrane Fuel Cells for Transportation," Proceedings of the World Renewable Energy Congress VIII, 29 August-3 September 2004, Denver.

[7] J. Larminie and A. Dicks, "Fuel Cell Systems Explained,” 2nd Edition, Wiley, Chichester, 2003.

[8] M. Granovskii, I. Dincer and M. A. Rosen, "Life Cycle Assessment of Hydrogen Fuel Cell and Gasoline Vehicles,” International Journal of Hydrogen Energy, Vol. 31, No. 3, 2006, pp. 337-352. doi:10.1016/j.ijhydene.2005.10.004

[9] ISO 14040:2006 Environmental Management-Life Cycle Assessment-Principles and Framework.

[10] ISO 14044:2006 Environmental Management-Life Cycle Assessment-Requirements and Guidelines.

[11] CONCAWE/EUCAR/EC-JRC-IES Report, "Well-toWheels Analysis of Future Automotive Fuels and Power trains in the European Context," Well-to-Wheels Report, Version 2c, March 2007.

[12] M. Pehnt, “Assessing Future Energy and Transport Systems: The Case of Fuel Cells, Part 2: Environmental Performance," International Journal of Life Cycle Assess- 
ment, Vol. 8, No. 6, 2003, pp. 365-378.

doi:10.1007/BF02978510

[13] M. Pehnt, "Life-Cycle Assessment of Fuel Cells Stacks," International Journal of Hydrogen Energy, Vol. 26, No. 1, 2001, pp. 91-101.

[14] B. Sorensen, "Total Life-Cycle Assessment of PEM Fuel Cell Car,” Paper 3-1189, Proceedings of the 15th World Hydrogen Energy Conference, Yokohama, 27 June-2 July 2004.

[15] J. Ally, "Life Cycle Assessment of the Hydrogen Fuel Cell, Natural Gas and Diesel Bus Transportation Systems in Western Australia,” Murdoch University, Report for the Government of Western Australia Department for Planning and Infrastructure, Perth, 2008.
[16] M. Granovskii, I. Dincer and M. A. Rosen, "Life Cycle Assessment of Hydrogen Fuel Cell and Gasoline Vehicles,” International Journal of Hydrogen Energy, Vol. 31, No. 3, 2006, pp. 337-352.

[17] Monografías Enerxe, "PEMFC—Pilas de Combustible de Membrana de Intercambio Protónico,” Monografías Enerxe, Plataforma Tecnolóxica Galega de Enerxía, Vol. 3, 2009. http://www.enerxe.org

[18] http://fuelcells.org (access in January 2011).

[19] S. Ramesohl and F. Merten, "Energy System Aspects of Hydrogen as an Alternative Fuel in Transport," Energy Policy, Vol. 34, No. 11, 2006, pp. 1251-1259. 